\section{Disentangling the bank}

John Lawton

Perspectlves in Ecological Theory. Edited by Jonathan Roughgarden, Robert M. May and Simon A. Levin. Princeton University Press: 1989. Pp.394. Hbk $\$ 60$; pbk $\$ 22.50$.

Too many field ecologists hate theory. How can the tangled bank, in all its glorious, muddy complexity, be reduced to a set of antiseptic differential equations? To be fair, it isn't certain that it can; but to presume that we cannot hope to find general rules for the way nature works is to reduce every ecological interaction to a special case, to be marvelled at and then added to the vast rummage box of wonderful anecdotes and special cases. Certainly, ecological systems are complex, sometimes bewilderingly so; a humble English meadow may be home to more like a thousand species than a hundred. Nevertheless, there are sufficient regularities and patterns in nature to suggest that there are rules and regulations underlying the tangle.

The present book has its origins in a growing sense of alarm and frustration about the apparently widening rift between theoreticians and field workers in ecology, and between pattern seekers and the gee whiz school of wonderful anecdotes. In an attempt to forge closer links between both sides of the divide, some 40 ecologists representing the broad sweep of the subject met in Asilomar, California, in 1987. The fruits of their labours are displayed in these Perspectives.

There are eight main sections, spanning the core of theoretical ecology, including population dynamics, species interactions, ecology and evolution, community and ecosystem processes, and resource management. With one exception, each section contains two review chapters followed by a discussion chapter in which one of the participants attempts to draw together the threads of what politicians often refer to as "frank and wide-ranging discussions". In the main this format works very well.

For those who require convincing that empirical ecologists need theory to guide their work, Kareiva's chapter, entitled "Renewing the Dialog between Theory and Experiments in Population Ecology", is essential reading; the few short paragraphs on pages $78-80$ ought to be engraved in the hearts and minds of all aspiring ecology graduates, and those of their teachers. If this fails to move them, then Powell's simple observation that "we simply cannot afford to wait for the data to pour in to determine what the future may bring for our planet" should do the trick. Developing theoretical ecology is not just an absorbing intellectual exercise. It isn't even a matter of life and death; it's much more important than that.

The book has many strengths. Not least, it provides a gold mine of interesting and important questions, sufficient to keep armies of graduate students profitably employed for several years. Perhaps more importantly it defines an agenda for research initiatives to be undertaken by the entire community. For example, a theme repeated in at least eight chapters is the problem of how ecologists should deal

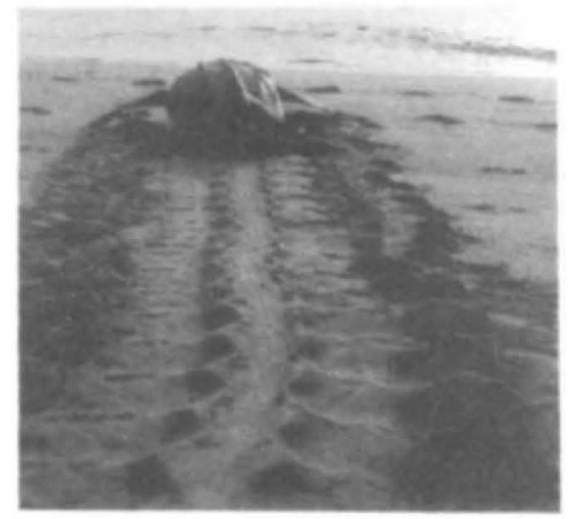

Tracking back - a female turtle returns to sea after laying her eggs. The picture is reproduced from the chapter on population dynamics in the new, fifth edition of Biology, by Helena Curtis and N. Sue Barnes, published by Worth.

with and model nested hierarchies of spatial and temporal scales. The question emerges in such disparate areas as plant physiological ecology (Chapter 1, by Gross), behavioural ecology and resource acquisition (Chapter 2, by Pulliam), ecosystem structure and function (Chapter 16, by Levin) and forest simulators (Chapter 17, by Horn, Shugart and Urban). Two contributions are devoted entirely to the problem, one general and wide-ranging by O'Neill and the other more specific, on physical and biological scales of variability in aquatic ecosystems, by Powell. Although no clear answers emerge about how we should deal with the problem, it is a sign of the growing maturity of ecology that such wildly different subject areas should converge on essentially the same set of abstract, general questions.

From the many other key issues raised by the book, I will select just two. In the discussion on ecosystem structure and function (Chapter 18), Schlesinger asks whether "some species, or some ecosystems, are more important to global function than others". And in Chapter 20, Pimm and Gilpin review the role of theoretical ecology in conservation biology. As species and entire ecosystems vanish before the flood-tide of humanity, I can think of no more pressing fields of research.

Of course, there are weaknesses. Not all the chapters are as thoughtful, insightful and new as they could and should have been. Indeed, one or two are little more than skimpy rehashes of rather tired themes; fortunately, they are few.

I also think two things are lacking. First, there is little attempt, anywhere in the book, to ask what are the main patterns and regularities in nature that ecologists wish to explain. Tilman (in the discussion to the section on population dynamics and species interactions, Chapter 6) and Cody (in the discussion on structure and assembly of communities, Chapter 15) both emphasize the urgent need to document major patterns, a view that I entirely endorse. But it is not a message that most of the writers have acted upon, except perhaps implicitly. Cohen (Chapter 13) is a notable exception, providing a masterly account of patterns in food webs, together with a unifying hypothesis to explain them.

Second, the book contains a sampling of theoretical ecology, not a comprehensive review. Perhaps it was never intended to do more than select some of the high ground in the centre of the range of possibilities. Nevertheless, it is a pity that some intriguing theoretical questions have not found a place. Many are new, or poorly worked - for example questions about why there are more small species than large species in the world; whether there are hard limits to global diversity; and what determines the size, shape and limits of species' geographical ranges. Many of the issues that form the core of the book have been around for half a century and more. It is good to see real progress being made towards answering them, at last; but it would have been even better to see clearer signposts to the next mountain range.

If Perspectives in Ecological Theory succeeds, as I believe it will, in interesting more field workers to take an interest in theory, and more theoreticians to attempt to explain what is really going on out there, rather than what they imagine is going on, and to couch their models in testable'form, it will be a valuable contribution to the literature. Whether we like it or not, ecologists have to start giving hard answers to some very hard questions. Without a sound theoretical base for our subject, we will be unable to meet the challenges of the next decade and beyond. Revelling in the complexity of the tangled bank is simply not an option any more.

John Lawton is Director of the Centre for Population Biology and Professor of Community Ecology at Imperial College, Siiwood Park, Ascot, Berkshire, SL5 7PY, UK. 